\title{
PROPUESTA DE UNIDADES DE PAISAJE AGRARIO DE LA REGIÓN METROPOLITANA DE BARCELONA ${ }^{1}$
}

\author{
Valerià PAÜL i CARRIL \\ Institut d'Estudis Territorials - Universitat Pompeu Fabra/Generalitat de Catalunya \\ Joan TORT i DONADA \\ Departament de Geografia Física i Anàlisi Geogràfica Regional - Universitat de Barce- \\ lona \\ Gemma MOLLEVÍ i BORTOLÓ \\ Centre d'Étude et de Recherche sur la Vigne et le Vin - Université Michel de Montaigne \\ Bordeaux 3
}

\begin{abstract}
RESUMEN: Planteamos y desarrollamos una propuesta de unidades de paisaje agrario para la Región Metropolitana de Barcelona (Cataluña, España). El estudio se encuadra en el contexto del renovado interés por la consideración de los paisajes agrarios que se detecta en la investigación y en la práctica ordenadora de los últimos años. Abordamos inicialmente las cuestiones de orden teórico, y explicitamos a continuación las coordenadas metodológicas en que nos movemos. Más allá de estas pautas, el cuerpo del trabajo consiste en el análisis sintético de las 23 unidades de paisaje que hemos detectado y establecido en el ámbito territorial de referencia. Finalmente la investigación nos lleva a subrayar la necesidad de priorizar la atención a los paisajes agrarios en la planificación y la ordenación actual y futura del ámbito metropolitano. Unos paisajes que, tal como argumentamos en el texto, deben ser entendidos tanto en una perspectiva formal como funcional, y fundamentados en una base productiva que les otorgue coherencia e identidad $\mathrm{y}$, en definitiva, les permita dar continuidad a su razón de ser.

PALABRAS CLAVE: Ordenación del territorio; paisajes agrarios; unidades de paisaje; valores y funciones productivas del paisaje agrario; Región Metropolitana de Barcelona.

ABSTRACT: This paper provides an overview of the agrarian landscape units for the Barcelona Metropolitan Region (Catalonia, Spain). The context for this study is the renewed recognition of the value of agrarian landscapes in the scientific literature and planning practice in recent years. Initially theoretical questions are considered, followed by an explanation of the methodological coordinates that frame the identified work. The key thrust of this paper is devoted to the systematic analysis of 23 agrarian landscape units defined in the case study area. Finally, the research reinforces the importance of taking into account the agrarian landscapes in metropolitan planning and management agenda, both now and into the future. These landscapes, as it is explained in the paper, should be considered through a morphological perspective as well as by means of a functional approach. It is argued that agrarian landscapes should continue on a pro-
\end{abstract}

\footnotetext{
${ }^{1}$ Esta contribución se inscribe en el marco del proyecto «Los paisajes de la agricultura en España. Paisajes mediterráneos y canarios» (SEJ2006-15331-C02-02/GEOG), financiado por el Ministerio de Educación y Ciencia. Una primera versión de este artículo se presentó en 2005 como comunicación al X Colóquio Ibérico de Geografia. En dicha comunicación figuraba aún Roser Majoral i Moliné (1942-2005) como coautora, pues durante años impulsó a los que escriben este texto a trabajar en la línea de los paisajes agrarios. Por desgracia no hemos podido seguir disfrutando de su compañía y de su maestría, en ésta y en otras tantas direcciones.
} 
ductive basis, thereby providing identity and consistency and thus, enabling the continuity of its raison d'être.

KEY WORDS: Spatial/regional/urban planning/management; agrarian landscapes; landscape units; productive functions and values of the agrarian landscapes; Barcelona Metropolitan Region.

$\boldsymbol{R} \boldsymbol{E} \boldsymbol{S} \boldsymbol{U} \boldsymbol{M E}:$ Nous envisageons et développons une proposition d'unités de paysage agraire pour la Région Métropolitaine de Barcelone (Catalogne, Espagne). L'étude est encadrée dans le contexte d'intérêt rénové pour la considération des paysages agraires repérée dans la recherche et dans l'aménagement des dernières années. Tout d'abord, nous traitons les questions d'ordre théorique, puis les coordonnées méthodologiques dans lesquelles le travail se déroule. Au-delà, le corps du travail se consacre à l'analyse synthétique des 23 unités de paysage obtenues et établies dans l'aire territoriale de référence. Finalement la recherche entraîne de souligner la nécessité de prioriser l'attention sur les paysages agraires dans la planification et l'aménagement présent et futur de l'aire métropolitaine. Des paysages que, tel que nous justifions dans le texte, doivent être compris aussi bien à travers d'une perspective formelle que fonctionnelle. Ainsi ils s'appuient sur une base productive leur attribuant une cohérence et une identité qui, en définitive, leur permettent de donner continuité.

MOTS CLÉ : Aménagement du territoire ; paysages agraires ; unités de paysage; valeurs et fonctions productives du paysage agraire; Région Métropolitaine de Barcelone.

RESUMO:. Formulamos e desenvolvemos uma proposta de unidades de paisagem agrária para a Região Metropolitana de Barcelona (Catalunha, Espanha). O estudo enquadra-se no contexto do renovado interesse pela consideração das paisagens agrárias que se detecta nas pesquisas e na prática de ordenamento dos últimos anos. Inicialmente abordamos as questões de ordem teórica, e explicitamos a seguir as coordenadas metodológicas em que nos movemos. Além destas pautas, o corpo do trabalho consiste na análise sintética das 23 unidades de paisagem que detectamos e estabelecemos no âmbito territorial de referência. Finalmente a pesquisa leva-nos a sublinhar a necessidade de priorizar a atenção às paisagens agrárias na planificação e no ordenamento actuais e futuros do âmbito metropolitano. Umas paisagens que, tal como argumentamos no texto, devem ser entendidas tanto numa perspectiva formal como funcional, e fundamentadas numa base produtiva que lhes outorgue coerência e identidade, em suma, lhes permita dar continuidade à sua razão de ser.

PALAVRAS CLAVE: Ordenamento do território; paisagens agrárias; unidades de paisagem; valores e funções produtivas da paisagem agrária; Região Metropolitana de Barcelona.

\section{PLANTEAMIENTO INICIAL}

El paisaje de la Región Metropolitana de Barcelona $^{2}$ se caracteriza primordialmente por la impronta de sucesivas fases de urbanización, pero todavía pueden observarse en él, de forma significativa, tramas agrarias. La importancia de

\footnotetext{
${ }^{2}$ La Región Metropolitana de Barcelona es entendida en este estudio como el ámbito metropolitano establecido por la Llei 1/1995, de 16 de març, per la qual s'aprova el Pla territorial general de Catalunya; esto es, comprende siete comarcas: Alt Penedès, Baix Llobregat, Barcelonès, Garraf, Maresme, Vallès Occidental y Vallès Oriental (en total: $3.241,5 \mathrm{~km}^{2}$ y 4.841 .365 hab. en 2006). A pesar de que esta delimitación no goza de consenso académico ni de conciencia popular en muchas de las comarcas concernidas, presenta problemas aún mayores optar por una delimitación más amplia, o más reducida, eventualmente invocada por los propios autores.
} 
tales tramas no se debe considerar solo de forma cuantitativa (es decir, en términos de superficie), sino sobre todo desde el punto de vista cualitativo. Es razonable que aproximaciones paisajísticas de conjunto, como la del Atlas de los Paisajes de España (MATA Y SANZ, 2003), opten por caracterizar el paisaje de la parte central de la región de referencia como fundamentalmente urbano, pero en un análisis más detallado los paisajes agrarios deben ser objeto de mayor consideración. De hecho, el porcentaje de los espacios agrarios sobre el total de la superficie regional -un 17\% según el censo agrario de 1999- puede parecer nimio. No obstante, tal «nimiedad» debe matizarse al menos en dos direcciones. Por un lado, en algunos municipios se alcanza una cifra muy superior; en ellos, es habitual que la agricultura constituya paisajes de dimensiones considerables, por ejemplo en el Alt Penedès o en el Vallès Oriental (PAÜL Y TONTS, 2005). De otra parte, este $17 \%$ se debe poner en relación con el $16 \%$ que los espacios urbanos e industriales ocupan en la región. Por tanto cabe concluir que, aun en estrictos términos cuantitativos, los espacios agrarios tienen en la región de estudio una importancia destacable.

En cualquier caso, creemos que la relevancia de los paisajes agrarios barceloneses se debe buscar básicamente en su significación cualitativa. Una significación que tiene, a nuestro juicio, un fundamento triple: la situación geográfica, el valor en términos de identidad y la variedad formal. En cuanto al primer fundamento, debemos hacer notar que hablamos de una región metropolitana activa y expansiva, sometida a múltiples tensiones y a un crecimiento urbano ostensible, en la cual los paisajes agrarios representan «oportunidades» en múltiples direcciones ${ }^{3}$. En lo que al segundo fundamento se refiere, cabe mencionar que los paisajes agrarios constituyen referentes culturales de primer orden en la región, hasta el punto que la idea de «paisaje» en algunas de las comarcas del área (en particular el Vallès y el Penedès) está directamente asociada a un determinado tipo de paisaje agrario (PAÜL ET AL., 2005; PAÜL, 2007; PAÜL Y CALLAU, 2007). Por lo que respecta a la variedad formal, no es ocioso subrayar que nos encontramos ante el resultado de un largo proceso histórico de colonización humana, cuyas «claves paisajísticas» podemos leerlas hoy tanto en sentido sincrónico como diacrónico. De hecho, la creación de paisajes productivos a las puertas de una ciudad suele responder a unas lógicas específicas; unas lógicas que acaban creando un «diferenciación paisajística» mucho más acusada de lo que cabría esperar de una estricta atención a los factores físicos. Paisajes agrarios, periurbanos y no periurbanos, como veremos, se encuentran bien representados actualmente dentro de la región barcelonesa. Representados, en todo caso,

\footnotetext{
${ }^{3}$ Se desarrollará esta aseveración más adelante.
} 
de un modo mucho más significativo de lo que podríamos pensar en una primera aproximación.

Como punto de partida señalaremos que la idea de paisaje que tomamos como referente apunta, por un lado, al aspecto fisionómico del territorio y, por otro lado, a los valores, imágenes y cualidades vinculados al mismo. Se trata de una idea situada en la línea de planteamientos de la geografía explícitamente globalizadores o integrales (ORTEGA CANTERO, 1987, 2004; MARTÍNEZ DE PISÓN, 1998). Nos distanciamos, por tanto, de un entendimiento específico del paisaje en términos de construcción cultural. También dejamos de lado una posible consideración del paisaje como sistema explicable de forma objetiva y aséptica, o exclusivamente como forma de un territorio, obviando su cobertura cultural y perceptiva. En definitiva, nuestra forma de entender el concepto que nos ocupa entra dentro de lo que se ha dado en denominar «el paisaje de los geógrafos» (DONADIEU Y PÉRIGORD, 2005, 34).

Precisamente, en el seno de la tradición geográfica los paisajes agrarios han sido objeto de una continuada atención. Pero la geografía no se ha aproximado a estos paisajes de forma neutra, sino primando en ellos determinados aspectos. Concretamente, ha puesto énfasis en unos valores y ha privilegiado unos atributos -y no otros- en su análisis e interpretación. Tres han sido, por regla general, los más utilizados: los usos del suelo -con más propiedad, cultivos y coberturas del suelo-, el parcelario - producto tanto de circunstancias históricas como de la morfología del terreno- y el poblamiento (LÓPEZ ONTIVEROS, 2003). Los tres aparecen, por lo menos, desde MEYNIER (1959), la primera obra que ofrece una sistematización general de los paisajes de la agricultura en Europa y que en realidad es deudora de multitud de aproximaciones individuales anteriores a escala regional y comarcal. En una aproximación reciente, MATA $(2004,113-114)$ ha reajustado estas tres categorías en cinco apartados que también, en cierto modo, hunden sus raíces en la tradición paisajística de la geografía agraria:

1. La trama parcelaria, reflejo de los regímenes de apropiación y tenencia de la tierra.

2. Elementos construidos como bancales, azudes, acequias, norias, cortavientos, etc.

3. La red de caminos.

4. El poblamiento.

5. Los usos del suelo.

El estudio de paisajes agrarios tomando estos elementos como «marcadores interpretativos» o «señas distintivas» ha resurgido en los últimos años. Durante el auge cuantitativista y radical cayeron en un cierto desuso; lo prueba, a nuestro modo de ver, que parte de los análisis compilados en un libro de esa etapa, 
hito en el tema que nos ocupa en España, precisamente titulado Los paisajes rurales de España (VVAA, 1980), se distancie de esta óptica. No obstante, hoy en día han recobrado actualidad, tanto en España como en el extranjero. Como ejemplos internacionales de interés, en relación con el proceso mencionado, pueden verse las aportaciones relativas a geografía agraria en un libro reciente sobre comentario de paisajes (MADORÉ, 2006), en el que se utilizan los conceptos clásicos con renovada vigencia, o bien la obra dirigida por BRUNET (1992) sobre paisajes rurales en Francia.

En todo caso, debe quedar claro que los atributos mencionados son, en sí mismos, una convención, como lo son construcciones culturales como la idea de huerta, el paisaje agrario periurbano por antonomasia, que en sentido estricto es un mito romántico cuya conformación debe mucho a la geografía (Rosselló, 2004) ${ }^{4}$. Pero esto, opinamos, no invalida la tradición geográfica, sino que la emplaza en su lugar: aproximarnos a los paisajes agrarios de la forma que tradicionalmente se ha hecho desde la geografía, y de la forma que aquí seguiremos, nos sitúa en las coordenadas, aludidas más arriba, de «el paisaje de los geógrafos».

Nuestro propósito esencial en el presente trabajo es, en cualquier caso, establecer una tipología general de las unidades de paisaje agrario de la Región Metropolitana de Barcelona. Tipología que, de hecho, entendemos como el primer paso de una investigación más amplia, centrada en el análisis (descripción y explicación) sistemático de varios paisajes agrarios de España. Con carácter previo al referido análisis, hemos querido plantear un epígrafe en el que repasamos la actualidad de los paisajes agrarios en la región de Barcelona.

\section{LA REVALORIZACIÓN DE LOS PAISAJES AGRARIOS BARCELONESES}

En nuestra opinión, en los últimos años la percepción general de los paisajes agrarios de la Región Metropolitana de Barcelona está cambiando de forma significativa. Tal cambio lo podemos concretar en tres puntos esenciales. De un lado, existe un número creciente de colectivos sociales que muestra una sensibilidad particular hacia los paisajes agrarios. De otro, el paisaje se está convir-

\footnotetext{
${ }^{4}$ Más recientemente, la idea de huerta se divulga gracias a obras generales de Europa que, de forma algo incoherente, han ido repitiendo mapas que, de tanto reiterarse, parecen acabar convirtiéndose en algo «objetivo», cuando estas cartografías no son más que una interpretación esquemática de la realidad, por otro lado bastante imprecisa -caso, muy en particular, de individualizar huerta como categoría paisajística y distribuirla en determinadas áreas, como hace el mapa de Meeus y otros (1990) que, años después, apareció en el conocido como Informe Dobříš (Stanners y Bourdeau, 1998).
} 
tiendo en un argumento clave para el futuro del sector agrario en general, y de los entornos metropolitanos en particular. Finalmente, se detecta en la administración actual un incremento del interés hacia todo lo que concierne al paisaje. El estado de cosas actual contrasta con cierta actitud de «olvido» hacia los paisajes agrarios prodigada en anteriores etapas; actitud que ha sido perceptible tanto en el ámbito académico como al nivel de las administraciones públicas y en la perspectiva de la ordenación del territorio y del urbanismo. De hecho, aún hoy en día se producen intervenciones u opiniones algo disonantes en relación con los paisajes agrarios. A algunas de estas intervenciones haremos referencia en los próximos epígrafes, en los que desarrollamos los tres puntos esenciales que acabamos de señalar.

\section{Hacia una sensibilidad paisajística de amplio calado}

El análisis coordinado por NEL·LO (2003) sobre los denominados conflictos territoriales constituye un trabajo básico para el conocimiento de la dinámica territorial catalana en el momento actual. En él se ha puesto de manifiesto que los valores ecológicos, territoriales y paisajísticos están bastante asumidos por el común de la sociedad. En efecto, las movilizaciones por la protección del territorio se han expandido, superando el estadio en que eran patrimonio de elites ecologistas bien informadas. Con tales movilizaciones no solo se ha apuntado hacia la defensa de las singularidades ecológicas sino, cada vez más, hacia la preservación de la identidad de los paisajes, esto es, de las formas representativas de determinados territorios y de sus valores culturales (TORT Y FONT, 2004). De hecho, las peculiaridades naturales en buena medida ya se encuentran protegidas por la multiplicidad de figuras existentes en la región de estudio. En este contexto, los espacios que merecen una atención mayor por parte de los actores sociales, dada su fragilidad, son los agrarios (PAÜL, 2006, 2007). En tales movilizaciones los argumentos de paisaje son un lugar común, y es frecuente que los pagesos concernidos en cada una de las polémicas (o sus organizaciones representativas) participen o muestren simpatía con las reivindicaciones que se plantean. Puede servir de ejemplo el planteamiento defendido por algunos colectivos del Alt Penedès -en el que participan, también, agricultores-en el sentido de incluir el paisaje de viñedos de la comarca en la lista de patrimonio de la humanidad de la UNESCO; una inclusión que curiosamente se propugna desde una concepción del territorio en que se ve compatible el «hecho paisajístico» del Penedès con el «hecho urbano y metropolitano» de Barcelona:

«Es necesario definir un proyecto de futuro que permita integrar los valores culturales, ambientales y paisajísticos de este territorio [del Penedès] con la metrópolis, para poder asumir una función regional de calidad capaz de vincular culturalmente la sociedad de la región metropolitana con el espacio agrario, para 
constituirse en el campo de la ciudad y establecer un modelo avanzado de sostenibilidad. $[\ldots]$

«El concepto de ciudad sostenible no puede materializarse sin campo, sin medio rural. Está claro que hoy la gran mayor parte de los productos agrícolas y ganaderos consumidos en la región metropolitana no vienen de su entorno, pero, para el imaginario colectivo, la ciudad sin su entorno agrario es culturalmente empobrecedora y hasta pedagógicamente perversa.» (ASSOCIACIÓ PER AL DESENVOLUPAMENT DE LA MARCA PENEDÈS, 2003, s.p. $)^{5}$

La implicación de colectivos de agricultores en este tipo de movilizaciones es explícita. Baste decir que diversas asociaciones y sindicatos agrarios han sido los artífices de la salvaguarda de espacios como el Delta del Llobregat, el entorno agrario de Sabadell o la zona de Gallecs. De hecho las propias entidades participan en algunos de los órganos de gestión creados ad hoc (Parc Agrari del Baix Llobregat ${ }^{6}$ o Espai Rural de Gallecs ${ }^{7}$ ). Cabe apuntar, por otro lado, que estos órganos están impulsando políticas específicas de paisaje; por ejemplo, el Parc Agrari mediante el Plan rector de ambientación y calidad paisajística, en fase de elaboración.

Se podría argumentar que esta nueva sensibilidad hacia los paisajes agrarios está teñida de ambientalismo, de forma que el espacio agrario es percibido como reserva de biodiversidad, como área de conectividad, como recurso ambiental o ecológico, y/o como ámbito para la sostenibilidad; en definitiva, que toda esta «cobertura perceptiva verde» puede implicar que en cierto modo se olvide la dimensión productiva de todo espacio agrario (PAÜL, 2007). Sin embargo, en el territorio que nos ocupa, el parámetro ambiental es un valor aludido más. Un valor preponderante en algún caso, pero que en general no impide que la dimensión productiva, determinante en la conformación de los espacios agrarios, se siga viendo como relevante. Los movimientos sociales de los últimos años en la región de Barcelona, a pesar de vincularse a la iniciativa de muchos casos de grupos ecologistas, cuentan con payeses en su seno y defienden los espacios (y particularmente los paisajes) agrarios: en la región del Penedès; pero también

\footnotetext{
${ }^{5}$ Todas las traducciones al español son nuestras.

${ }^{6}$ Organismo creado en 1998, inicialmente mediante un consorcio formado por la Diputació de Barcelona, el Consell Comarcal del Baix Llobregat y la Unió de Pagesos. Posteriormente se le añadieron los 14 ayuntamientos implicados y, en 2006, la Generalitat de Catalunya. Véase, al respecto, CALLAU Y PaÜL (2007).

${ }^{7}$ Consorcio formado en 2002 entre los ayuntamientos de Mollet del Vallès y Parets del Vallès. Recientemente se ha substituido este consorcio por uno que agrupa cuatro municipios más y la Generalitat, denominado Consorci del Parc de l'Espai d'Interès Natural de Gallecs - designación que, dicho sea de paso, parece sesgada, por tratarse de una campiña cerealista (el apelativo evidencia, por sí mismo, una notable inclinación ambientalista).
} 
en la del Vallès. En este último caso, de hecho, la sociedad civil ha reclamado un Parc Agrícola del Vallès (mediante una propuesta muy elaborada, presentada públicamente el 2005) y, en la II Conferència dels Espais Naturals de la Plana del Vallès (octubre de 2007), se ha organizado una sesión entera dedicada a las actividades agrarias.

\section{La incorporación del paisaje en la ordenación del territorio}

A la par de la creciente sensibilización social sobre la materia, las instituciones catalanas han respondido a las demandas de forma más o menos sensible, como lo testimonia la aprobación de la primera carta del paisaje en Cataluña, la del Alt Penedès, elaborada a instancias de los principales actores sociales y económicos de la comarca y firmada por todos ellos a finales de $2004{ }^{8}$ En la región de Barcelona recientemente se ha empezado a trabajar en una segunda carta, la del valle de la riera de Argentona (Maresme), y otros tantos lugares podrían iniciar un proceso semejante. ${ }^{9}$ De hecho, la denominada Ley del Paisa$\mathrm{je}^{10}$ ha significado un hito de primera magnitud en la incorporación a la legislación catalana de todo el caudal de recomendaciones, prácticas, normas y planes que recoge el Convenio Europeo del Paisaje (CORTINA, 2006). En este contexto, dos circunstancias recientes que afectan a la ordenación del territorio catalán contribuyen a realzar el interés de las administraciones por los paisajes agrarios: la elaboración de un nuevo plan metropolitano para la región de Barcelona, por un lado, y la creación del Observatori del Paisatge, por otro. Las consideraremos con más detalle.

El plan territorial metropolitano es, en palabras de Esteban (2003, 33), una «materia pendiente» desde la aprobación en 1983 de la ley básica de ordenación del territorio en Cataluña. ${ }^{11}$ Cumpliendo lo dispuesto en la ley de paisaje, que faculta la creación de catálogos de paisaje asociados a los planes territoriales de las siete regiones catalanas, está garantizado que el paisaje sea un argumento clave en este plan territorial parcial -de hecho, se ha empezado a trabajar en ve-

\footnotetext{
${ }^{8}$ Una carta del paisaje es un instrumento de naturaleza relativamente indefinida, y de hecho la ley del ramo de Cataluña (ver nota al pie 10) la ha amparado de forma laxa: «son los instrumentos de concertación de estrategias entre los agentes públicos y los privados para llevar a cabo actuaciones de protección, gestión y ordenación del paisaje que tengan por objetivo mantener sus valores». La bibliografía francesa sobre la materia aporta procedimientos y metodologías específicas para su elaboración (GOGEU Y JENKINS, 1995), pero su capacidad de incidir sobre la realidad queda sujeta a lo que determine cada carta en concreto.

${ }^{9}$ El Parc Agrari, por ejemplo, así lo contempla en su programa de acción para el próximo bienio 2008-2010.

${ }^{10}$ Llei 8/2005, de 8 de juny, de protecció, gestió i ordenació del paisatge.

${ }^{11}$ Llei 23/1983, de 21 de novembre, de política territorial.
} 
rano de 2007 en el catálogo de paisaje metropolitano, y el propósito es ir confeccionándolo en paralelo al plan territorial de la región, que se está redactando desde la llegada de la coalición de izquierdas al gobierno catalán (2003). Además, la versión de plan metropolitano que se llegó a terminar a finales de los años noventa, pero que no fue aprobada, contenía determinaciones ordenadoras específicas para los espacios agrarios e incluso una diagnosis paisajística general de la región (SERRATOSA, 1999; PAÜL, 2006); convertida esta versión en referente insoslayable de cualquier ulterior plan metropolitano, el paisaje estará previsiblemente presente en el plan metropolitano que, según las intenciones del gobierno, debiera aprobarse de forma definitiva en la presente legislatura 2006-2010.

En lo que se refiere al Observatori del Paisatge, consorcio de asesoramiento a la Generalitat en materia de paisaje, las tareas que éste ha desarrollado desde su creación en 2004 han sido muy intensas. A efectos nuestros, tiene especial importancia la supervisión de los catálogos del paisaje -los primeros en fase de aprobación son los del Camp de Tarragona y Ponent. Para la elaboración de catálogos el Observatori ha realizado un documento de bases de gran interés teórico y metodológico (NoGUÉ Y SALA, 2006). Previsiblemente, la política de paisaje será incisiva en los espacios agrarios, partiendo de la base que los espacios considerados «de interés natural» (mayoritariamente forestales) ya están «blindados», y que lo urbano tiene una tradición de planeamiento propia que se refleja específicamente en la escala urbanística. Y decimos «previsiblemente» porque los espacios que no se han tendido a ordenar, y que por tanto, han sufrido mayores transformaciones territoriales y paisajísticas son los rurales en general, y los agrarios en particular (NOGUÉ, 2006). En estos ámbitos la política del paisaje debe ser capaz de incidir de manera especial, sobre todo en la medida que la administración agraria se ha desentendido en general de la dimensión territorial de sus propias políticas (PAÜL, 2006; PAÜL, CALLAU Y MONTASELL, 2007).

Desde el punto de vista del urbanismo y de la ordenación del territorio, los espacios agrarios han sido tradicionalmente marginados y relegados a la condición de «reserva para el crecimiento urbano» (LLOP, 2003). Sin embargo, en los últimos años se impone desde la práctica urbanística una mayor consideración de los denominados «suelos no urbanizables» y, dentro de ellos, de los espacios agrarios (SABATÉ, 2000, 2003; LLOP, 2003; MATA, 2004; JORNET, 2006). ${ }^{12} \mathrm{Y}$

\footnotetext{
${ }^{12}$ Acertadamente, la reciente Ley 8/2007, de 28 de mayo, de suelo cambia esta denominación de "suelo no urbanizable», aunque está por ver de qué forma las CCAA adaptan el nuevo modelo a su ordenamiento jurídico y si, una vez más, en los próximos años el Tribunal
} 
no hay duda que en esta renovada consideración urbanística gana especial importancia la dimensión paisajística de tales ámbitos. En este sentido, también se puede decir que, a escala de proyectos municipales, el paisaje agrario está poco a poco haciéndose un lugar por la vía urbanística. Hay ejemplos bastante concluyentes en la región de Barcelona en los últimos años: a los ya aludidos del Parc Agrari del Baix Llobregat o de Gallecs, cabría sumar iniciativas de planeamiento urbanístico en trámite en lugares como les Cinc Sènies de Mataró, el espacio agrario de Rials (Alella) o el Parc Agrari de Sabadell.

\section{El paisaje en el futuro de los espacios agrarios}

Si bien es cierto que la valoración social de los paisajes agrarios está aumentando y que las administraciones responden en cierta medida a esta sensibilidad, no lo es menos que la base física de estos paisajes - los espacios agrarios- atraviesa por lo general, en términos económicos, una fase delicada. Las causas de este «momento de crisis» son diversas y su consideración excede, de hecho, las posibilidades de este artículo. En todo caso, más que estructurales, nos parecen coyunturales y variables en función del segmento productivo. Sea como fuere, en la perspectiva general de la agricultura europea, es evidente que el paisaje es percibido como un valor añadido de primer orden, en particular por lo que se ha dado en denominar «multifuncionalidad» del mundo rural (MATA, 2004; FOLCH, 2006). Un valor que cobra una especial significación en los contextos metropolitanos, a pesar de que está siendo sometido a crítica precisamente en lo que a la aplicación en áreas periurbanas se refiere (HOLMES, 2006). En este sentido, el paisaje agrario puede ayudar a complementar las rentas de las actividades agroganaderas, pero no se debe perder de vista que tales actividades son productivas y que solo se entienden en tanto que existe una producción agraria. Si se diluye la función productiva del paisaje agrario estaremos hablando de un «paisaje», pero con unos atributos no necesariamente ligados a lo que implica el adjetivo «agrario».

Desde determinadas ópticas se han puesto en cuestión los argumentos productivos para la defensa de la agricultura y de los paisajes agrarios. Es cierto, de entrada, que las actividades agrarias deben alejarse de parámetros de corte productivista y primar más lo cualitativo que lo cuantitativo; también es deseable que la producción tienda hacia la sostenibilidad y atienda a cuestiones ecológicas, minimice los impactos y reduzca determinadas herencias de la revolución verde, apuntando hacia la agricultura integrada e incluso hacia la ecológica. Sin embargo, a nuestro modo de ver, cuando desde ópticas neoliberales se ar-

Constitucional estima que hay que volver a delimitar el radio de acción del poder legislativo autonómico y del estatal y, por lo tanto, trastocar de nuevo las leyes. 
guye a favor de la entrada masiva de productos agrarios de fuera de la UE y se vaticina el fin de las explotaciones agrarias en el continente, se oculta deliberadamente que en los países en vías de desarrollo hay salarios bajos y faltan sindicatos fuertes, y que, además, los beneficios del comercio internacional de bienes agrícolas recaen en los intermediarios (no en los productores en origen). Por otro lado, como la experiencia de NAFTA ha demostrado, los más beneficiados de la apertura de mercados en materia agrícola son los agricultores de Estados Unidos y Canadá, y no los de Méjico (FONTANA, 2005), por lo que los beneficios en términos de desarrollo de regiones menos favorecidas no están nada claros. «Renunciar a mantener nuestra producción agraria y resignarnos a la dependencia de abastecimientos externos significa aceptar un riesgo muy serio en caso de producirse una crisis natural, o una de política internacional, a la vez que implica degradar nuestra condición de vida, condenándonos a alimentos de calidad inferior [...], en un sacrificio que ni servirá para que los campesinos $[\ldots]$ africanos vivan mejor [...] ni para que nosotros tengamos estos alimentos a precio más bajo, pues cuando haya desaparecido la competencia local no habrá ninguna razón para mantener precios diferenciales» (FONTANA, 2005, 115116). Finalmente, hay quien cree que el campo en la región de Barcelona se mantiene gracias a las ayudas de la PAC; pero esta opinión es discutible para la mayor parte de los paisajes agrícolas de la región de estudio, y suele encubrir un profundo desconocimiento de la materia. Los agricultores de hortalizas, mayoritarios como veremos más adelante, no reciben ayudas directas a la producción; en este caso, el mantenimiento de la agricultura se explica porque se trata de un negocio rentable. Por otro lado, la consideración de una producción europea globalmente excedentaria ${ }^{13}$ debe ser matizada, en el sentido de hacer referencia fundamentalmente a producciones agroindustriales y continentales. En cualquier caso, es evidente que tal consideración no puede extenderse de un modo acrítico al ámbito de la horticultura o la fruticultura de calidad y con garantías.

En el momento actual, y por lo que respecta a nuestro sector de estudio, algunas cifras resultan muy ilustrativas de la situación que acabamos de apuntar. MONTASELL (1998) estima, por ejemplo, que un 75\% de la producción del Baix Llobregat y del Maresme tiene como destino el mercado central metropolitano MERCABARNA - del que se distribuye a prácticamente todos los mercados municipales. Esta circunstancia permite deducir que el referido porcentaje de producción se consume en su mayor parte en Barcelona y cercanías. Este dato es interesante en términos de vínculo directo campo-ciudad, aunque ciertamente

\footnotetext{
${ }^{13}$ Como, por ejemplo, afirma ANDRÉs (2004) para justificar la urbanización de predios rurales en Murcia.
} 
deberían mejorarse la comercialización, la trazabilidad y los circuitos cortos. Los productos de calidad de la región (cerezas y melocotones de Ordal, alcachofas del Prat, fresas del Maresme, etc.) siguen siendo valorados por el consumidor barcelonés, pero es un problema que los productos no siempre se identifiquen como tales -e, igual de problemático, que no se indique que buena parte de la producción que entra a MERCABARNA desde el Baix Llobregat es integrada, pues con este proceder no queda explicitado su valor añadido. Según datos de MERCABARNA, el 25\% de la entrada de frutas y verduras al mercado procede de las comarcas del Baix Llobregat y del Maresme: una región con una capacidad productiva tal no debería permitirse el lujo, volviendo a los planteamientos de FONTANA (2005), de perderla.

Los argumentos expuestos hasta aquí nos ponen ante la evidencia que los paisajes agrarios de la región de Barcelona constituyen un motivo por sí mismos para reforzar y poner en valor la producción que los sustenta. Producción que no se debería valorar a la ligera. En este sentido, conviene no ignorar que los paisajes constituyen en muchos casos unas imágenes potentes que pueden ayudar al consumidor, cada vez más exigente, a valorar lo que adquiere y, de paso, a reforzar el vínculo con el lugar de producción. El estudio de redes de cooperativas de distribución de productos en Barcelona está poniendo de manifiesto que los consumidores quieren tener garantías de la calidad de los productos que compran, e incluso, si es posible, conocer de qué explotaciones proceden. A menudo, los consumidores de las cooperativas de distribución van a visitar al pagès $\mathrm{y}$ a interesarse por sus campos: quieren tener garantías, también, de un paisaje agrario de calidad que vinculan a una agricultura de calidad. Y prácticamente lo mismo se podría decir de las visitas a las pequeñas caves del Alt Penedès, en las que no solo «se vende» el cava o el vino, sino, también, en cierto sentido, el paisaje (BRUSIS, 2006) ${ }^{14}$. En definitiva, paisaje agrario y producción agraria en la región de estudio son dos conceptos directamente asociados (y su potencial disociación significaría tender hacia paisajes temáticos, y no agrarios). Por todos estos motivos podemos concluir que la idea de paisaje agrario es especialmente pertinente en el momento actual.

\section{CONSIDERACIONES METODOLÓGICAS}

Existe ya una abundante bibliografía que permite proceder al trabajo que nos proponemos con garantías suficientes, como por ejemplo el trabajo dirigido por GÓMEZ MENDOZA (1999) para la Comunidad de Madrid o el aludido de MATA

\footnotetext{
${ }^{14}$ Dicho sea de paso, el sector del vino y el cava, en su conjunto y con sus subsectores asociados, es el primer segmento económico del Alt Penedès. Convendría no perder de vista este hecho, como sucede con frecuencia.
} 
Y SANZ (2003) para el conjunto de España, coincidentes en buena medida con los planteamientos de las referencias internacionales sobre la materia ${ }^{15}$. Tampoco faltan relevantes reflexiones teórico-metodológicas sobre la cuestión (véase, por ejemplo, PÉREZ-CHACÓN, 2002 en un sentido general, y MATA, 2006 para los paisajes agrarios en particular). Para nuestro entorno inmediato, el manual aludido sobre catálogos de paisaje en Cataluña (NOGUÉ Y SALA, 2006) constituye una referencia ineludible. De todos modos, conviene decir que no se han podido seguir las recomendaciones del Observatori en lo que se refiere a número de unidades totales a delimitar, pues sus planteamientos son para el conjunto de una región y nuestra contribución se centra solo en los paisajes agrarios. Tampoco las tareas de BUSQUETS ET AL. (2004) o BUSQUETS (2006), relativas al mapa de unidades de paisaje del Alt Penedès, pueden ser un modelo a seguir, dado que están elaboradas a escala comarcal y, por tanto, a efectos nuestros, a una escala demasiado detallada. Todos estos trabajos nos han servido en múltiples sentidos a la hora de proceder al trabajo, partiendo de la base que entendemos por unidad de paisaje un ámbito de características relativamente homogéneas, individualizado por uno o varios atributos, y que posee una lógica interna. «Aquella combinación de elementos que genera una fisionomía particular, una organización morfológica diferenciada y diferenciable que hace a una parte del territorio distinta de otra» (MATA, 2006, 218). A ello cabría añadir, partiendo de la concepción de paisaje antes defendida, toda la «cobertura perceptual» (imágenes, valores, etc.) que se asocia a cada unidad. En más de un caso en nuestra región de estudio la unidad de paisaje es, no solo una unidad fisionómicamente diferenciada, sino a la vez una unidad percibida, defendida, culturalmente recreada y/o tradicionalmente tratada o sentida como homogénea.

Los atributos que fundamentalmente hemos empleado son los tres indicados más arriba -usos del suelo, parcelario y poblamiento-, así como el aludido de las imágenes y los valores. Para los tres primeros, el trabajo de campo ha sido fundamental, completado, en el caso del parcelario, por el SIGPAC ${ }^{16}$ y por investigaciones específicas de regímenes de tenencia y propiedad (MAJORAL, 1988, 2002; MOLINERO ET AL., 2004; PAÜL, 2005, 2006), así como por estudios en determinadas áreas sobre la relación entre morfología del terreno y estructura fundiaria. El trabajo de los usos del suelo se llevó a cabo inicialmente mediante la explotación de los datos del Censo Agrario de 1999 a escala municipal (MAJORAL, 2002; MOLINERO ET AL., 2004; PAÜL, 2005, 2006) y la observación

${ }^{15}$ Caso del manual de Gogeu y JenKIns (1995) para la elaboración de cartas de paisaje, en el que se especifica de qué forma se deben escoger y ordenar las entités paysagères o unidades de paisaje.

$16 \mathrm{http} / / /$ sigpac.mapa.es/fega/visor 
atenta de los ortofotomapas a 1:25 000 del Institut Cartogràfic, pero en una segunda fase recurrimos a fuentes más detalladas y complementamos los trabajos con observaciones sobre el terreno. En cuanto al poblamiento, el trabajo de campo materializado en fotografías, bocetos y planos de casas es el único procedimiento disponible para la obtención de información, aunque el insuperado ensayo de LLOBET (1958) da pistas y sugerencias aún hoy plenamente válidas. Finalmente, en lo que se refiere a la imagen del territorio y a sus valores socioculturales, las investigaciones parten de varios años de estudio, y se basan en la observación sistemática de representaciones paisajísticas, tanto desde el punto de vista de la «alta cultura», como desde aproximaciones más cotidianas, populares o reivindicativas (TORT, 2004; MOLLEVÍ, 2005; PAÜL ET AL., 2005; PAÜL Y SERRANO, 2005; PAÜL, 2006, 2007; PAÜL Y CALLAU, 2007). Dicho esto, conviene insistir en que no tomamos los usos del suelo como atributo exclusivo para proceder a la distribución en unidades de paisaje. Como se ha señalado en otras ocasiones, los usos del suelo constituyen un criterio de primer orden para aproximaciones generales a escalas pequeñas (VVAA, 1980; MATA, 2001), pero en el caso de trabajos a escala regional debe ser completado con otros criterios, como de facto se produce en la aproximación a los paisajes rurales de Madrid de GÓMEZ MENDOZA (1999).

Pretendemos básicamente plantear un análisis, descriptivo y explicativo a la vez, de las unidades de paisaje agrario que hemos obtenido de nuestra investigación. Nuestro objetivo es que estas unidades sirvan de base para el debate que está a punto de producirse alrededor del catálogo de paisaje de la región de Barcelona. Los espacios agrarios de la región deben estar correctamente representados y tratados en éste y puede resultar útil, a tal fin, contar con trabajos previos de base orientados, además, en esta dirección temática. Optamos por una exposición de los resultados similar a la de GóMEZ MENDOZA (1999, 100-102): concisa, breve y simple, y que ponga énfasis en lo más característico. Obviamos otros resultados obtenidos de nuestra investigación, como la correlación de los paisajes más significativos con el planeamiento urbanístico y los proyectos territoriales, que nos ha permitido detectar una serie de conflictos asociados. Por otra parte, tampoco hemos recogido aquí las sugerencias de «calidad paisajística» que podrían ser consideradas en futuros documentos de ordenación y gestión del territorio. En cualquier caso, el carácter de los materiales con que hemos trabajado nos ha llevado a elaborar una presentación que hiciera énfasis en los contenidos gráficos. Por este motivo hemos incluido una cartografía general y una antología fotográfica.

A efectos metodológicos es importante destacar que esta investigación ha tenido muy en cuenta trabajos «clásicos» sobre la materia que nos ocupa. La línea de trabajo de paisaje agrario dio lugar en Cataluña a unas aportaciones tan des- 
tacables como las de Vila (1930), DefFonTAINES (1949) o LLOBET (1947, 1955). En los tres casos, el ámbito de estudio quedaba comprendido dentro de los límites de la actual región metropolitana barcelonesa. Por tal motivo, a efectos de nuestro trabajo los consideramos como unos antecedentes obligados; de hecho, numerosos autores ya han señalado su extraordinario valor geográfico (MAJORAL, 1979; TORT, 2004; PAÜL, 2006; PANAREDA, 2007; SANS Y PANAREDA, 2007). Finalmente, debemos subrayar que la investigación que aquí presentamos se vehiculó en cierta medida a través de las tesis doctorales de dos de los autores de este trabajo (MOLLEVÍ, 2005; PAÜL, 2006). ${ }^{17}$

\section{UNA BREVE PRESENTACIÓN DE LAS UNIDADES DE PAISAJE AGRARIO DE LA REGIÓN METROPOLITANA DE BARCE- LONA}

A continuación procedemos a describir las distintas unidades de paisaje detectadas en la región. Cada unidad se trata en un párrafo, encabezado por el enunciado que hemos empleado y que se localiza también en la cartografía y las fotografías que acompañan al texto.

1. La huerta de y los regadios del embalse de Foix. Situada en una pequeña área llana del litoral, encontramos la zona que se caracteriza por el aprovechamiento agrario del río Foix. Tal aprovechamiento se realiza mediante el embalse homónimo, construido a principios del siglo XX y cuyas aguas empezaron a utilizarse para regar desde mediados de ese siglo. Los elementos que caracterizan a esta unidad son la existencia de regadío y la presencia de las hortalizas. Morfológicamente se detectan en esta unidad tramas que responden a varios orígenes: parcelarios rectilíneos procedentes de la desecación de las marismas litorales, parcelarios adaptados a la suave topografía de la llanura de Vilanova (terrazas con paredes de piedra seca), etc. De hecho, puede hablarse de una matriz predominante de regadío pero con una significativa presencia del secano, generalmente algarrobos abandonados o viñas aún en producción. No obstante, la huerta tradicional de Vilanova i la Geltrú, irrigada por norias, ha desaparecido con el crecimiento de la ciudad. Los retazos de paisaje agrario que quedan en sus alrededores se encuentran entre urbanizaciones e implantaciones industriales, en la parte más interior de la llanura litoral, justo por debajo del recorrido de uno de los canales que se inician en la presa del Foix. En lo que respecta a las antiguas marismas, los campos aún en producción son escasos, aunque presentan todavía una calidad formal destacable. En esta unidad de paisaje llaman también la atención numerosas mansiones rurales, distribuidas de forma dispersa y caracterizadas por sus grandes dimensiones y por una estética particular.

${ }^{17}$ Ambas se encuentran en este momento en curso de publicación. 
2. Los viñedos del Garraf. En el contacto de los términos municipales de Vilanova y Sant Pere de Ribes, pasado el canal procedente del Foix, desaparece el regadío y se impone el secano, aún en morfología de llanura. En este sector domina la viña y se hacen visibles los rasgos propios del poblamiento del interior del Penedès. El conjunto adquiere homogeneidad por la presencia de viñedos, a pesar de los esporádicos olivos, y alcanza su máxima expresión alrededor de Sant Pere de Ribes. Probablemente el lugar con una mayor resonancia cultural de esta unidad sea Sitges, donde existió la tradición de cultivar la vid para el vino de malvasía, alabado y emparentado (por la vía del mito) con la traída de cepas por Roger de Flor desde el Mediterráneo oriental. Hoy, en Sitges, no queda prácticamente una sola hectárea ni de viña ni de cualquier otro cultivo, por lo que ya no es posible contemplar desde la población el «hermoso plantío de las viñas» descrito por Madoz (1850, XIV, 409-410) en su Diccionario.

3. Las hondonadas vitícolas de Garraf-Ordal. Desde Canyelles hasta Begues, a lo largo del macizo calcáreo de Garraf-Ordal, la complejidad topográfica ha condicionado con fuerza la presencia humana. Los asentamientos antiguos suelen aparecer en las hondonadas más anchas, los fondos, con presencia de materiales finos que permite una estimable productividad de los suelos. Es el caso de Oleseta o Viladellops; centros de población que conforman, con su respectivo entorno, una constelación de pequeñas islas agrarias dentro de una matriz general de matorral de palmito y coscoja. En estos lugares el aprovechamiento actual es fundamentalmente vitícola. De todas formas, allí donde hay materiales finos suficientes, se prefieren los cereales a las viñas (así lo muestran lugares como Begues, Campdàsens o el Pla d'Ardenya). En esta unidad de paisaje el impacto de canteras y urbanizaciones ha sido especialmente importante; tal impacto no repercute solo en las laderas sino también en las llanuras y, por tanto, afecta a significativos retazos agrarios (caso de Begues o Oleseta).

4. Los viñedos del llano del Penedès. De entrada debemos subrayar el fuerte carácter paisajístico del sector central de la comarca del Alt Penedès. El llano vitícola del Penedès, surcado por multitud de pequeños arroyos, se inscribe dentro de cuatro cuencas hidrográficas diferentes, pero perceptivamente constituye un todo difícilmente reductible: un verdadero «mar de viñas» jalonado por multitud de pueblos, caseríos y masías. Nos parece muy interesante el valor que los ciudadanos de la comarca dan a este paisaje, profundamente connotado de signos de identidad. Este paisaje, de hecho, ha sido en los últimos años el escenario de las más intensas movilizaciones en pro de la protección paisajística de la región.

5. Los llanos cerealistas del sector de las sierras prelitorales correspondiente al Penedès. A diferencia de lo que sucede en la franja litoral de los Catalánides, en el Penedès, las sierras prelitorales contienen unas depresiones internas bas- 
tante amplias y cubiertas de sedimentos de un cierto grosor. En realidad no se trata de sectores pequeños, como los fondos de la unidad 3 , sino de verdaderos sinclinales rellenados por margas. Estas depresiones se encuentran fundamentalmente ocupadas por cereales, de tal forma que prolongan hacia el sur los rasgos paisajísticos generales de las comarcas centrales catalanas. Los campos conforman una matriz de grano grande, con márgenes redondeados para facilitar el labradío, y el poblamiento se encuentra concentrado en pequeños núcleos que suelen ocupar el centro de cada depresión.

6. El policultivo de los valles del Anoia. La riera de Lavernó, tributaria del Anoia, que riega en sus inicios una buena parte de la llanura descrita en la unidad 4, comienza a encajarse a medida que busca el nivel de base del río al que afluye. Por ello genera, ya en Sant Sadurní d'Anoia, una morfología sinuosa, con altos precipicios y frecuentes cárcavas. En general, todos los valles tributarios del río Anoia tienden a cierta compartimentación entre sí, y sus incisivos cursos fluviales siguen el patrón descrito para la riera de Lavernó; nada que ver, por tanto, con una llanura. El uso del suelo aquí predominante son los viñedos, pero son habituales, también, los almendros, los olivos y los cereales. A lo largo de los ríos, huertos intermitentes hacen acto de presencia (sobre todo en el valle del río Mediona) y, en sectores concretos, como en la Fortesa, nos encontramos con vergeles de producción intensiva de frutales, melocotón sobre todo, facilitados por el agua de riego. En todo caso, es un paisaje agrario variado que alterna con zonas de bosque y que puede conceptuarse, en algunos lugares -como en las aldeas de Can Benet de la Prua o del Bedorc-, de una gran calidad formal.

7. Los olivares del Pla de Montserrat. El piedemonte de Montserrat constituye un área extensa de olivares que conforma uno de los paisajes olivareros por excelencia de Cataluña. El aceite de Olesa siempre ha tenido fama y es el producto característico de esta unidad, que se extiende del Bruc hasta Olesa de Montserrat. A pesar de haber sufrido una reducción progresiva en las últimas décadas, la zona aún conserva superficies de olivar bastante destacadas -de una gran calidad formal gracias a la original composición de los cultivos y a la orografía circundante. Algunas explotaciones han apostado recientemente por la producción de aceite de calidad y ecológico, recuperando prensas y variedades de oliva tradicionales, pero se trata de un espacio sometido a una presión urbanística muy fuerte.

8. Los frutales del entorno de Martorell. Esta unidad se extiende de forma discontinua por las vegas de los ríos Llobregat y Anoia, en las cercanías a su confluencia. Se trata de los frutales relícticos que en parte se habían beneficiado del regadío, por ejemplo del canal Gomis-Alegre. Pero han venido a menos, y si aún se conservan es porque su distribución actual se corresponde a grandes ras- 
gos con superficies inundables. Buena parte de estos frutales presenta el típico parcelario de regadío, fino y rectilíneo, asociado a canales. En algunos de estos campos se ha ido produciendo una sustitución de frutales por maíz u hortalizas, en un proceso paralelo a la pérdida de valor comercial de las producciones tradicionales.

9. Los frutales de la Vall Baixa. Los frutales de la Vall Baixa responden a la producción intensiva de fruta fresca -manzana, pera, ciruela y melocotón sobre todo- orientada al consumo de Barcelona e incluso a la exportación, como fue común antes de la guerra civil. Constituyen un genuino paisaje agrario de regadío, organizado a partir de dos canales paralelos al río (Infanta Carlota y Dreta del Llobregat), construidos en el siglo XIX, de los cuales parte una red de acequias perpendiculares a los canales. Este pequeño sector fue definido por RUBIÓ I TUDURÍ $(1932,72)$ como una «incomparable fábrica de productos» de huerta, fruto de «un trabajo varias veces secular» y merecedor, por ende, de una protección máxima frente a la urbanización. Pero la clara orientación ordenadora de Rubió Tudurí no cuajó, y varias infraestructuras lineales han reducido al mínimo lo agrario en la Vall Baixa.

10. El Delta del Llobregat. Conforma uno de los paisajes más característicos de la región, y puede considerarse como el resultado por excelencia del carácter intensivo de la agricultura a las puertas de una gran ciudad. Con regadío desde finales del siglo XIX (facilitado por el descubrimiento de aguas artesianas), se caracteriza por una producción intensiva de hortalizas, unos parcelarios de grano fino, y la existencia de grandes masías. Los magistrales análisis de DEFFONTAINES (1949) y de CODINA $(1971,1975)$ sobre este espacio, de un gran potencial en términos de imagen geográfica, permiten pensar en una ordenación paisajística acorde con su categoría. Sin embargo, la ciudad que dio origen a este paisaje es también, desde hace décadas, el foco de los procesos que están en la base de su progresiva degradación. Campañas de defensa de este territorio, a menudo protagonizadas por payeses -como Salvem el Pla, desde finales de los años setenta-, han conducido finalmente a la creación del Parc Agrari del Baix Llobregat, que engloba los últimos sectores del Delta que se mantienen en explotación.

11. Las denominadas «valls dels cirerers». Cuando a finales del siglo XIX la filoxera arruinó las cepas de las montañas de Ordal, la alternativa escogida fue la plantación de cerezos. Tal especialización agronómica, con variedades autóctonas, se mantiene actualmente en estos valles de morfología abrupta y cultivo en bancales o terrazas. Los materiales predominantes en esta unidad son pizarras y conglomerados con una característica coloración rojiza. El aprovechamiento de estos últimos para la construcción de los muros de las terrazas da lugar a algunos de los conjuntos paisajísticos más destacables de la región. Torre- 
lletes es seguramente el lugar más especial en este sentido. Cabe señalar que la cereza de Ordal es muy apreciada en Barcelona, donde se distribuye de forma individualizada en algunos mercados.

12. El denominado «hort i vinyet» de Barcelona. Esta unidad tiene hoy una significación superficial irrisoria, pero es el testimonio de la persistencia de un paisaje agrario asociado desde la alta edad media a Barcelona: el mosaico de huertos y viñedos que se distribuía por el llano barcelonés y que era fuente de alimentación de la ciudad intramuros. La distinción básica dentro de este paisaje se daba entre la huerta propiamente dicha, asociada al Rec Comtal, y los espacios de secano; el Rec Comtal es un canal, de origen muy antiguo, que se construyó para proveer agua a Barcelona desde Montcada. De todo este «hort $i$ vinyet» en la actualidad no queda más que el recuerdo, y por tanto no es posible observar el «conjunto superior a toda explicación, más propio de una pintura poética que de una narración» que FRANCISCO DE ZAMORA (1785[1973], 32) describió; sin embargo aún subsiste un pequeño retazo alimentado por el Rec Comtal, con el parcelario de regadío y una producción de hortalizas. Su futuro es incierto, ya que el sector que ocupa está calificado como suelo para equipamientos.

13. Los «anfiteatros» hortícolas de la Serra de Marina. La unidad está constituida por pequeños «circos» abiertos al mar, muy soleados, en los que las masías, a veces torres aburguesadas, se sitúan a media vertiente. La parte alta de los valles es hoy superficie forestal, mientras que en la parte basal se conservan huertos confundidos con jardines residenciales. En el Canyet, la Vallençana, Pomar, etc., las pequeñas parcelas son un juego entre hortalizas y jardines, todas ellas regadas por pozos y minas, y en ocasiones estructuradas en terrazas y bancales. La unidad se puede considerar un típico paisaje mediterráneo promisсио.

14. Los viñedos de Alella. Los viñedos de Alella son considerados como la fuente de caldos por excelencia de las buenas mesas de Barcelona. Más allá de esta tradición, cabe decir que los viñedos se encuentran primordialmente en las vertientes soleadas de las montañas graníticas del Baix Maresme. Aunque la mayor parte de la superficie vitícola tradicional de Alella y sus alrededores ha sido urbanizada o abandonada, en sectores concretos como Rials, Vallcirera o el entorno de la iglesia de l'Alegria se pueden rastrear aún conjuntos de viñedo bien conservados. En cualquier caso cabe señalar que la normativa vigente ha permitido que la denominación de origen de Alella amparase municipios del otro lado de la sierra; es decir, terrenos situados a umbría, cuya producción históricamente poco tuvo que ver con Alella. 
15. Los cultivos bajo plástico del Baix Maresme. Cuando LloBet (1955) escribía sobre la agricultura del Maresme, explicaba que en el Baix Maresme se daba una orientación evidente hacia la floricultura, introducida en los años veinte por un agricultor italiano, y aportaba para ilustrar su comentario numerosas fotos de campos cubiertos de flores (tulipanes, claveles, nardos) emparradas en cañas o barras de madera. No se intuía entonces que a partir de 1960 se generalizarían en ese lugar los invernaderos, primero de hierro y cristal, después de plástico, instalados sobre los antiguos bancales de la llanura litoral del Maresme. La consecuencia del proceso ha sido la conformación de un paisaje característico, un «mar de plástico» de producción intensiva de flor, y crecientemente de planta ornamental, sin duda favorecido por la instalación en 1983 del Mercat de la Flor i la Planta Ornamental en Vilassar de Mar.

16. Las huertas del Maresme central. De Cabrera de Mar hacia el norte, los invernaderos desaparecen y se suceden huertas generalmente libres de plástico. Estas huertas están situadas, como los invernaderos de la unidad 14 (aunque el laberinto de plásticos lo disimule), en una suave pendiente que se extiende desde el piedemonte hasta la línea de mar. Se organizan mediante pequeñas terrazas, con una evidente hiperparcelación, y con frecuencia están atravesadas por los arroyos que bajan de la montaña-rieres o rials, en el lenguaje local-, aprovechados antaño como caminos y en cuyos márgenes se construyeron estructuras de contención para evitar las inundaciones (motes). Este paisaje de huertas es sobre todo evidente en Cabrera de Mar y Mataró (les Cinc Sènies). Los cultivos son muy variados y cambian con la estación, con varias cosechas anuales. Es una huerta muy fecunda y parcialmente edificada, con multitud de pequeñas barracas para los aperos de labranza o para los motores que elevan el agua desde el subsuelo. En la comarca existe una fuerte conciencia sobre estos paisajes agrarios, en buena medida promovida por los propios agricultores.

17. Los campos de fresones del Alt Maresme. A partir de los años sesenta, en el Alt Maresme se generalizó el cultivo del fresón como alternativa a otras producciones tradicionales menos rentables. Entonces se extendieron las típicas estructuras bajo plástico por todas las laderas montañosas de esta parte de la comarca; laderas montañosas que, con su pendiente, permiten que no se pudra la fresa en las vertientes orientadas a mediodía. Los campos de fresón llegaron a cubrir grandes extensiones de esta zona y aún más allá, pero en los últimos años la competencia del sur de España y de otros países ha motivado una profunda crisis en el sector y es la causa de que muchos campos se encuentren abandonados y con una apariencia muy degradada. Recientemente, las instituciones han empezado la promoción del fresón del Maresme pero su producción está en declive y no se vislumbran alternativas de cultivo. 
18. El Delta del Tordera y los regadíos del Alt Maresme. La parte litoral más septentrional del Alt Maresme se caracteriza por una importante acumulación de sedimentos, sobre todo en el Delta del Tordera. Su colonización es reciente, pero la zona ya participó en la intensa producción de patata y hortaliza que caracterizó al Maresme en los años anteriores a la guerra civil. Paisajísticamente esta unidad se corresponde con una morfología de regadío, cuyo dibujo es todavía evidente en el espacio deltaico. En el resto del Alt Maresme, el perfil agrario se ha visto atenuado por el empuje turístico y urbanizador, sobre todo en Calella y Pineda. Sin embargo, en Santa Susanna se encuentra aún un importante retazo agrario (Pla d'en Balasc). El regadío se hace fundamentalmente por bombeo de agua del subsuelo.

19. La vega del Tordera. Si remontamos un poco el río Tordera, veremos como rápidamente los cultivos cambian y entramos en un paisaje agrario bastante parecido al de la parte central de la vecina comarca de la Selva: plantaciones de chopos, campos de forrajes y maíz, y grandes masías con granjas de bovino orientadas a la producción de leche. La vega del río ha ido perdiendo superficie cultivada a favor de polígonos industriales y logísticos, pero aún en las hondonadas que descienden del Montnegre, con llanuras de fondo de valle, encontramos numerosos campos de maíz y retazos de este peculiar paisaje agrario (un buen ejemplo lo constituyen los alrededores del vecindario de Sant Tou).

20. Los valles de cabecera de los cursos fluviales del Maresme. En medio de las sierras del Montnegre-Corredor encontramos unos valles dedicados a hortalizas, cuyo carácter común es la angostura de las hondonadas, encajadas entre montañas, que determinan una parcelación característica. Un prototipo de este paisaje se encuentra en Canyamars, pero también es perceptible, con algunos matices, en Arenys de Munt, en Dosrius o en Òrrius. Quizá JOSEP PlA (1976, 759) se refería a este paisaje cuando escribía: «Si con el murmullo del mar a la espalda nos internamos por los pequeños valles que forman, en su descenso, las montañas, encontraremos rincones tan soleados, de una calma tan plácida e idílica, $\tan$ perfumados de botánica meridional, tan claros de silencio y de aire, que vienen a ser como deliciosos oasis. Estos rincones suelen ser pequeños, cerrados, de una entrañable intimidad. A veces, un pueblo pequeñísimo queda como recluido dentro de la reducida cazuela de un valle».

21. Los llanos cerealistas del oeste del Vallès. El paisaje de cerros ondulados con cultivo mayoritario de cereales ha devenido, mediante una intensa reelaboración cultural, la imagen paradójicamente «típica» de una de las comarcas más industrializadas de Cataluña: el Vallès. En cualquier caso, como en todo paisaje asociado a una imagen, es difícil caracterizar de forma objetiva esta unidad sin caer en los tópicos. De hecho, en el Vallès actual la extensión de los cereales cebada mayoritariamente, pero también trigo y avena- es mayor que la de hace 
unos años, cuando existían aún numerosas huertas y bastantes viñedos. Desde un punto de vista paisajístico, los retazos agrarios que quedan se distribuyen en les cordales de pequeños cerros (carenes), mientras que las vegas han sido ocupadas por industrias y zonas residenciales. Por tanto, el esquema que explica esta unidad es una sucesión de bandas paralelas donde la agricultura se mantiene en las partes altas. Sólo en algún lugar excepcional, como Palaudàries o Gallecs, subsiste lo que podríamos denominar la agricultura de zonas llanas. Es importante subrayar la circunstancia que, aunque estemos hablando de uno de los territorios más urbanizados de la región metropolitana, la sociedad vallesana ha reivindicado con fuerza la preservación de lo agrario en varios lugares: el aludido Gallecs, Torre Negra, Torrebonica, etc. Además, la propia sociedad civil ha propuesto la creación del denominado Parc Agrícola del Vallès, que permitiría la conexión de los espacios agrarios que aún quedan.

22. Los campos de cereales, forrajes y regadios del este del Vallès. La parte más oriental de la llanura vallesana reproduce a grandes rasgos el mismo esquema físico de la anterior unidad. En este sector, de todos modos, el paisaje agrario es mucho más diverso y en parte aún contiene los elementos que el sector occidental ya ha perdido: agricultura en vegas, variedad de usos del suelo (cereales -cebada sobre todo-, maíz, forrajes y huertas asociados a los cursos y minas de agua), presencia de grandes explotaciones con masías en buen estado de conservación (el lugar de Marata es buen ejemplo al respecto), convivencia de usos agrarios y manchas forestales extensas, y pervivencia de arboricultura en determinados sectores (olivos en Samalús o Corró d'Amunt, avellanos en Santa Eulàlia de Ronçana o l'Ametlla, etc.). Como en todo el Vallès, el contraste entre llano y montañas es muy marcado y constituye un referente compositivo formal de primer orden. En esta unidad, principalmente en el entorno del Montseny, tiene aún cierta importancia la ganadería bovina orientada a la producción lechera, en consonancia con una tradición productiva que hizo del lugar, en determinados momentos, un hito fundamental para el abastecimiento de leche a la ciudad de Barcelona.

23. Los llanos cerealistas del Moianès. El paisaje de los alrededores de Castellterçol, aunque por lo general frondoso, tiene en los campos de cultivo y en las grandes masías un punto de referencia paisajístico muy destacable. Constituye el margen sur de un altiplano de la Depresión Central, el Moianès, inserto de lleno en el dominio de la montaña media del centro de Cataluña, que, aunque administrativamente en el Vallès, poco tiene que ver ya con los Catalánides. El perfil agrario de la zona toma como pauta las grandes explotaciones, que viven de la ganadería y mantienen extensas superficies agrarias dedicadas a cereales.

A las unidades de paisaje descritas habría que sumar los calveros agrarios que aparecen en los macizos montañosos de vocación forestal; se trata, fundamen- 
talmente, de extensiones pequeñas dentro de matrices paisajísticas predominantemente silvícolas. Gran parte de estos calveros, en buena medida de cereales, pero también de huerta y frutales, aparecen hoy relacionados con las pautas de gestión de los espacios protegidos. En tales contextos, las antiguas áreas de cultivo son a menudo tratadas como «reserva de biodiversidad», y suelen mantenerse para la alimentación de determinada fauna o bien se conciben como cortafuegos.

\section{A MODO DE CONCLUSIONES}

Como habíamos anticipado al comienzo, la diversidad agropaisajística de la región metropolitana de Barcelona es manifiesta y destacable. No hablamos simplemente en términos de calidad paisajística de las unidades descritas; hablamos también del valor de una heterogeneidad de morfologías agrarias singularmente relevante. Tales motivos justifican sobradamente que los paisajes agrarios, en el sentido amplio del concepto, sean tenidos en cuenta, de forma explícita y consciente, en todas las aproximaciones ordenadoras que afectan a la región metropolitana, a pesar de la diversidad de problemáticas que tiene el tratamiento de lo paisajístico agrario desde la planificación territorial (MATA Y FERNÁNDEZ MUÑOZ, 2004; MATA, 2004, 2006). No es suficiente, como en general sucede hasta ahora, que existan algunos instrumentos de orden declarativo o propuestas voluntaristas o meramente teóricas: es fundamental una implicación mayor de los gestores públicos en las políticas de preservación y mantenimiento de los paisajes agrarios. Sin esta premisa, cualquier política pretendidamente paisajística de los espacios agrarios no irá más allá del plano retórico.

En la medida en que la sociedad asuma de forma más generalizada los paisajes agrarios como propios - es decir, como unas tramas que contribuyen a la calidad de vida general-; en la medida que entienda que sus gestores -léase agricultores - son los primeros que deben ser tenidos en cuenta en dicha ordenación; y en la medida que comprenda que los paisajes son así porque responden, genuinamente, a una actividad económica productiva, podrá hablarse de un futuro activo para los paisajes agrarios, sin incurrir en desviaciones tipo «parque temático»o «reserva fosilizada». De hecho, hemos podido comprobar en distintos lugares que un intenso debate social, alentado por múltiples actores (en varias ocasiones, los propios agricultores), ha dado lugar a unas formas de ordenación más acordes con la entidad singular de los paisajes agrarios de la región (Parc Agrari del Baix Llobregat, Gallecs, etc.). Una región que, más allá de las transformaciones continuas que la afectan, debería ser consciente de todo lo que representa su extraordinario mosaico paisajístico. Esperemos, en este sentido, que el catálogo de paisaje en elaboración posibilite una «hoja de ruta» clara, explícita y contundente. 
Queremos aludir finalmente a un punto específico, relativo a los estudios geográficos. Señalábamos al inicio nuestra voluntad de enmarcar este trabajo en la línea de investigaciones sobre paisajes agrarios que, aunque en cierto olvido las últimas décadas, reaparece desde hace unos años. Creemos que no se debe perder de vista que la propia idea de paisaje es deudora de lo rural (TORT, 2003, 2006) y que, a pesar de que ésta pueda extrapolarse a otros ámbitos territoriales, y tenga en ellos innegables connotaciones de interés, no se tendría que desaprovechar u omitir la vertiente paisajística de los espacios agrarios y rurales. En este sentido entendemos que la geografía, como disciplina global y sintética del territorio, debería asumir un claro protagonismo en este debate, más allá de las posiciones un tanto pasivas que en ocasiones ha mostrado. En palabras del profesor García Fernández, que hacemos nuestras:

«Hoy lo agrario ha sido sustituido acertadamente por lo rural; pero [...] la SAU sigue siendo más lo primero que lo segundo. Y todo [el] énfasis se pone en la producción, y en los problemas, que en los momentos actuales, enfrenta. No hay por qué rechazarlo; pero no darle carácter de exclusividad. Pues con este economicismo se hace abstracción de los elementos de que consta esta economía rural, y que tienen clara manifestación en el territorio. Se da cuenta de lo que hay en éste; pero no de cómo está en él. Parece que la geografía ha dimitido de lo que es su objeto; dar imagen y explicar lo que se encuentra sobre la superficie terrestre; $y$ cómo afecta al grupo social que en ella vive» (GARCÍA FERNÁNDEZ, 2005, 18).

No quisiéramos terminar estas conclusiones sin una valoración metodológica final. Es innegable que todo trabajo de este tipo está sujeto a cierto grado de subjetividad; de hecho, sobre la elaboración de unidades de paisaje algún autor ha dicho que «il n'existe pas de vérité absolue» (GOGEU Y JENKINS, 1995, 55). Además, existía el riesgo de acabar considerando un número potencialmente infinito de unidades. Nuestros principios, al respecto, han sido simples: la adopción, por un lado, de un nivel de análisis mesoescalar (o de escala regional, en la terminología geográfica clásica), $\mathrm{y}$, por otro lado, la atención a la bibliografía existente sobre la materia y en relación con el ámbito geográfico estudiado. En síntesis, no se ha ido más allá de una propuesta, como establecíamos en el propio título del artículo. De un modo congruente con el planteamiento, creemos que los resultados pueden considerarse como un punto de referencia en diferentes sentidos. Y especialmente en uno: el de la necesidad de una toma de conciencia urgente acerca del significado de lo agrario y de lo rural en un ámbito geográfico tan complejo y tan polisémico como es hoy la Región Metropolitana de Barcelona.

\section{REFERENCIAS}

ANDRÉS, J.L. (2004): «Incertidumbres en el espacio agrícola y proceso urbanizador "resort" en la Región de Murcia», Cuadernos de Turismo, 14, 7-65. 
Associació Per Al Desenvolupament De La Marca Penedès (2003): La Marca Penedès. [Disponible en Internet: http://www.marcapenedes.org/presentacio.htm (consulta en setiembre de 2003)]

Brunet, P. (dir.) (1992): L'Atlas des Paysages Ruraux de France, Paris, Éditions JeanPierre de Monza.

BRusis, R. (2006): Pla estratègic de les rutes del vi i del cava de l'Alt Penedès, Barcelona, Cambra Oficial de Comerç, Indústria i Navegació de Barcelona.

BusQuets, J. (2006): «Estudio del paisaje vitivinícola del Alt Penedès. Análisis y establecimiento de criterios e instrumentos para la gestión del paisaje vitivinícola de la comarca del Alt Penedès», en: MATA, R. y TARROJA, À. (coords.): El paisaje y la gestión del territorio, Barcelona, Diputació de Barcelona, pp. 449-463.

Busquets, J.; CORTINA, A. Y FARRÉ, C. (dirs.) (2004): Estudi del paisatge vitivinícola de l'Alt Penedès, Sant Cugat del Vallès, LANDTRA/DTUM.

CALlaU, S. Y PAÜL, V. (2007): «Le Parc Agricole du Baix Llobregat: un moyen de préserver, développer et gérer un espace agricole périurbain». [Comunicación presentada al Colloque «Les agricultures périurbaines»: un enjeu pour la ville]

CoDINA, J. (1971): El Delta del Llobregat i Barcelona. Gèneres i formes de vida dels segles XVI al XX, Barcelona, Ariel.

CoDINA, J. (1975): «Closes i “openfield” al Delta del Llobregat», en Miscel-lània Pau Vila, Granollers, Montblanc-Martin, pp. 233-238.

CORTINA, A. (2006): «La ley de protección, gestión y ordenación del paisaje de Cataluña», en: MATA, R. Y TARROJA, À. (coords.): El paisaje y la gestión del territorio, Barcelona, Diputació de Barcelona, pp. 405-420.

DEFFONTAINES, P. (1949): «Le delta du Llobregat. Étude de géographie humaine», Revue Géographique des Pyrénées et du Sud-Ouest, 20, 137-174.

Donadieu, P. Y PERIGORD, M. (2005): Clés pour le paysage, Paris, Ophrys.

Esteban, J. (2003): «La Regió Metropolitana de Barcelona», Papers, 39, 31-41.

FoLCH, R. (2006): «Els reptes mediambientals de la producció i la transformació agroalimentària», en Primer Congrés del Món Rural a Catalunya, Barcelona, Generalitat de Catalunya, pp. 277-307.

FONTANA, J. (2005): «Les víctimes de la globalització a casa nostra: la pagesia», en La construcció de la identitat. Reflexions sobre el passat i sobre el present, Barcelona, Base, pp. 103-120.

GARCÍA FERNÁNDEZ, J. (2005): «El lenguaje de la geografía y el lenguaje de los geógrafos», Investigaciones Geográficas, 38, 5-22.

GoGeU, Y. Y JENKINS, C. (dirs.) (1995): La charte paysagère. Outil d'Aménagement de l'Espace Intercommunal, Paris, La Documentation Française.

Gómez MendozA, J. (dir.) (1999): Los paisajes de Madrid: naturaleza y medio rural, Madrid, Alianza.

HolmeS, J. (2006): «Impulses towards a multifunctional transition in rural Australia: Gaps in the research agenda», Journal of Rural Studies, 22, 142-160.

JORNET, S. (2006): «La gestión de espacios rurales en transición: los ejemplos de Gallecs y Les Cinc Sènies», en: MATA, R. y TARroJA, À. (coords.): El paisaje y la gestión del territorio, Barcelona, Diputació de Barcelona, pp. 569-583.

Llobet, S. (1947): El medio y la vida en el Montseny, Barcelona, CSIC. 
LLOBET, S. (1955): «De geografía agraria de la comarca del Maresme (Barcelona)», Estudios geográficos, 58, 23-72; 59, 215-297.

LloBet, S. (1958): «La casa rural», en: SOlÉ I SABARÍs, L. (dir.): Geografia de Catalunya, Barcelona, Aedos, vol. I, pp. 481-498.

LLOP, C. (2003): «De la reserva urbana al proyecto del territorio municipal. Del territorio asediado al territorio libre», en: FONT, A. (coord.): Planeamiento urbanístico, Barcelona, Diputació de Barcelona, pp. 151-168.

LÓPEZ ONTIVEROS, A. (2003): «Descubrimiento, conformación histórica y problemática de los paisajes rurales». [Ponencia del Seminario «Naturaleza y cultura del paisaje», parcialmente en: LÓPEZ ONTIVEROS, A. (2004): «Descubrimiento y conformación histórica de los paisajes rurales», en: ORTEGA CANTERO, N. (ed.): Naturaleza y cultura del paisaje, Soria/Madrid, Fundación Duques de Soria/UAM, pp. 123-148]

MADORÉ, F. (dir.) (2006): Le commentaire des paysages en géographie humaine, Paris, Armand Colin.

MAdOZ, P. (1850): Diccionario geográfico-estadístico-histórico de España y sus posesiones de ultramar, Madrid, La Ilustración, 16 vol.

MAJORAL, R. (1979): La utilización del suelo agrícola en Catalunya, Barcelona, UB, 2 vol. [Tesis doctoral]

MAJORAL, R. (1988): Dinàmica de les explotacions agràries a l'àmbit de la CMB, Barcelona, Gerència de Promoció Agrícola de la CMB, 2 vol.

MAJORAL, R. (coord.) (2002): Cataluña. Un análisis territorial, Barcelona, Ariel.

MARTíNEZ DE PISÓN, E. (1998): «El concepto de paisaje como instrumento de conocimiento ambiental», en: MARTÍNEZ DE PISÓN, E. (dir.): Paisaje y medio ambiente, Valladolid, Universidad de Valladolid/Fundación Duques de Soria, pp. 9-28.

MATA, R. (2001): «Los paisajes agrarios», en: GIL OLCINA, A. Y GÓMEZ MENDOZA, J. (coords.): Geografía de España, Barcelona, Ariel, pp. 299-327.

MAtA, R. (2004): «Agricultura, paisaje y gestión del territorio», Polígonos, 14, 97-137.

MATA, R. (2006): «Métodos de estudio del paisaje e instrumentos para su gestión. Consideraciones a partir de experiencias de planificación territorial», EN MATA, R. Y TARROJA, À. (coords.): El paisaje y la gestión del territorio, Barcelona, Diputació de Barcelona, pp. 199-239.

MATA, R. Y FERNÁNDEZ MuÑOZ, S. (2004): «La Huerta de Murcia. Landscape guidelines for a Peri-urban territory», Landscape Research, 29(4), 385-397.

MAta, R. y SANZ Herraiz, C. (dirs.) (2003): Atlas de los Paisajes de España, Madrid, Ministerio de Medio Ambiente.

MEEUS, J.H.A.; WiJERMANS, M.P. Y VROOM, M.J. (1990): «Agricultural Landscapes in Europe and their transformation», Landscape and Urban Planning, 18, 289-352.

MEYNIER, A. (1958): Les paysages agraires, Paris, Armand Colin.

Molinero, F.; MAJORAL, R.; GARCÍA BARTOlOMÉ, J.M. Y GARCÍA FERnÁNDEZ, G. (coords.) (2004): Atlas de la España rural, Madrid, Ministerio de Agricultura, Pesca y Alimentación.

Molleví, G. (2005): Geografia de la vitivinicultura en Catalunya, Barcelona, UB. [Tesis doctoral]

MONTASELL, J. (1998): «Análisis de la rentabilidad socio-económica del espacio agrario», en NEL·LO, O. (dir.): Dictamen sobre los espacios agrarios del Llobregat y la 
incidencia sobre los mismos de las actuaciones del convenio Delta, Barcelona, Institut d'Estudis Metropolitans de Barcelona, pp. 77-119.

Nel·Lo, O. (dir.) (2003): Aquí, no! Els conflictes territorials a Catalunya, Barcelona, Empúries.

NoGUÉ, J. (2006): «Diagnosis propositiva de las transformaciones territoriales y paisajísticas de Cataluña», en: TARROJA, À. y CAMAGNI, R. (coords.): Una nueva cultura del territorio, Barcelona, Diputació de Barcelona, pp. 565-576.

Nogué, J. Y SALA, P. (2006): Prototipus de catàleg de paisatge, Olot/Barcelona, Observatori del Paisatge. [Disponible en Internet: http://www.catpaisatge.net/fitxers/ Prototipus2006.pdf] (consulta en agosto de 2006)]

Ortega CANTERo, N. (1987): Geografía y cultura, Madrid, Alianza.

ORTEGA CANTERO, N. (2004): «Naturaleza y cultura en la visión geográfica moderna del paisaje», en: ORTEGA CANTERO, N. (ed.): Naturaleza y cultura del paisaje, Soria/Madrid, Fundación Duques de Soria/UAM, pp. 9-35.

PANAREDA, J.M. (2007): «La percepción del paisaje del Montseny (Cordillera Prelitoral Catalana) por Salvador Llobet a partir del Mapa de los Mantos de Vegetación de 1947», en: PAÜL, V. Y TORT, J. (eds.): Territorios, paisajes y lugares. Trabajos recientes de pensamiento geográfico, Cabrera de Mar/Madrid, Galerada/AGE, pp. 193-204.

PAÜL, V. (2005): «The Agricultural Diversity of Metropolitan Barcelona: The Sustainability of Agrarian Areas», en: MATHER, A.S. (ed.): Land Use and Rural Sustainability. Proceedings of Conference on Land Use and Rural Sustainability, Aberdeen, IGU Commissions on LUCC and Sustainability of Rural Systems, pp. 113119.

PAÜL, V. (2006): L'ordenació dels espais agraris metropolitans. Plans, gestió i conflictes a la regió de Barcelona, Barcelona, UB. [Tesis doctoral]

PAÜL, V. (2007): «"Paisajes de resistencia”. Acerca de las representaciones paisajísticas en algunos conflictos territoriales recientes en Cataluña», en: PAÜL, V. Y TORT, J. (eds.): Territorios, paisajes y lugares. Trabajos recientes de pensamiento geográfico, Cabrera de Mar/Madrid, Galerada/AGE, pp. 473-495.

PAÜL, V. Y CALlaU, S. (2007): «La identitat del territori vitivinícola del Penedès a l'entorn de Barcelona». [Ponencia del 1r Congrés d'Art i Paisatge Vitivinícola]

PAÜL, V. Y SERRANO, D. (2005): Muntanyes d'Ordal. El nom que no surt als mapes. Barcelona: Publicacions de l'Abadia de Montserrat.

PAÜL, V. Y TONTS, M. (2005): «Containing Urban Sprawl: Trends in Land Use and Spatial Planning in the Metropolitan Region of Barcelona», Journal of Environmental Planning and Management, 48(1), 7-35.

PAÜL, V.; CALlaU, S. Y MONTASELL, J. (2007): Elements clau de les polítiques territorials i sectorials amb implicacions per als espais agraris (amb especial consideració dels àmbits periurbans). Girona: Fundació Agroterritori.

PAÜL, V.; TORT, J. Y MAJORAL, R. (2005): «El paisaje como construcción geográfica. Un estudio sobre la imagen del territorio del Vallès (Catalunya)». [Comunicación presentada al II Coloquio del Grupo de Historia del Pensamiento Geográfico]

PÉREZ-CHACÓN, E. (2002): «Unidades de paisaje: aproximación científica y aplicaciones», en: ZoIdo, F. Y VENEGAS, C. (coords.): Paisaje y ordenación del territorio, Sevilla, Junta de Andalucía, pp. 122-135. 
Pla, J. (1976): Tres guies, Barcelona, Destino. [vol. 30 de la Obra Completa]

Rosselló, V. (2004): «Les hortes mediterrànies. Perspectiva llunyana d'un ideal anacrònic», Afers. Fulls de recerca i pensament, 47, 129-135.

RUBIÓ I TUDURÍ, N. (1932): El pla de distribució en zones del territori català (Regional Planning), Barcelona, Generalitat de Catalunya.

SABAtÉ, J. (2000): «El Parc Agrari del Baix Llobregat», Àrea, 8, 251-282.

SABATÉ, J. (2003): «Balance y perspectivas del planeamiento urbanístico municipal», en: Font, A. (coord.): Planeamiento urbanístico, Barcelona, Diputació de Barcelona, pp. 181-204.

SANS, J. Y PANAREDA, J.M. (2007): «El Delta del Llobregat visto por Pierre Deffontaines en 1949», en: PAÜL, V. Y TORT, J. (eds.): Territorios, paisajes y lugares. Trabajos recientes de pensamiento geográfico, Cabrera de Mar/Madrid, Galerada/AGE, pp. 205-217.

SERRATOSA, A. (dir.) (1999): Factors clau de la planificació territorial a l'àrea metropolitana de Barcelona, Barcelona, Institut d'Estudis Territorials.

StanNers, D. Y BourdeAu, P. (eds.) (1998): Medio Ambiente en Europa. El Informe Dobř $̌ s ̌ s$, Madrid, Agencia Europea de Medio Ambiente/Ministerio de Medio Ambiente.

TORT, J. (2003): «Obra pública i paisatge a Catalunya», en: TARRAGÓ, S. (ed.): Obres Públiques a Catalunya, Barcelona, Real Academia de Ingeniería, pp. 393-418.

TORT, J. (2004): Pau Vila. L'esperit de la terra, Barcelona, Publicacions de l'Abadia de Montserrat.

TORT, J. (2006): «Del pagus al paisaje: cinco apuntes y una reflexión», en: MATA, R. Y TARROJA, À. (coords.): El paisaje y la gestión del territorio, Barcelona, Diputació de Barcelona, pp. 699-712.

TORT, J. Y FONT, J. (dirs.) (2004): Paisatge i ordenació del territori, Barcelona, UB.

VILA, P. (1930): «El Vallès. Assaig geogràfic», en Comarca del Vallès, Barcelona, Casa del Vallès, pp. 1-83.

VVAA (1980): Los paisajes rurales de España, Valladolid, AGE.

ZAMORA, F. (1785-1789): Diario de los viajes hechos en Cataluña. [Publicado en: BOIXAREU, R. (ed.) (1973): «Diario de los viajes hechos en Cataluña» de Francisco de Zamora, Barcelona, Curial] 
Cartografía de la propuesta de unidades de paisaje agrario de la Región Metropolitana de Barcelona. Elaboración de Valerià Paül. Observación: La base de usos del suelo de 2002 proviene del Sistema d'Informació Ambiental (Generalitat de Catalunya). Disponible en Internet: http://mediambient.gencat.net (consulta en 07.2005)

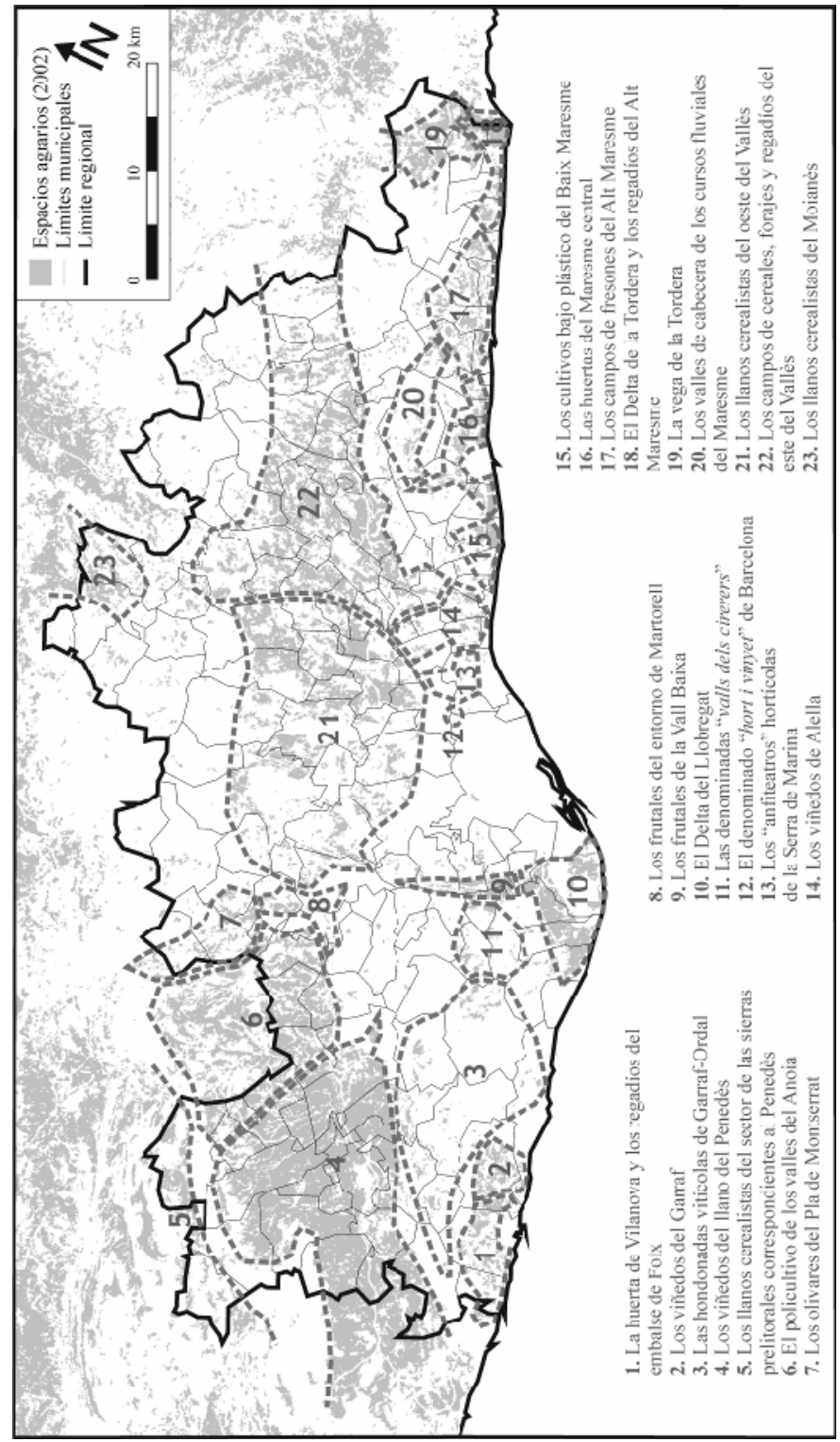


Antología de fotografías de las unidades de paisaje agrario de la Región Metropolitana de Barcelona (I).

Fotografías de Valerià Paül (04.2002-06.2005). Antología de fotografías de las unidades de paisaje agrario de la Región Metropolitana de Barcelona (I).

Fotografias de Valerià Paül (04.2002-06.2005).

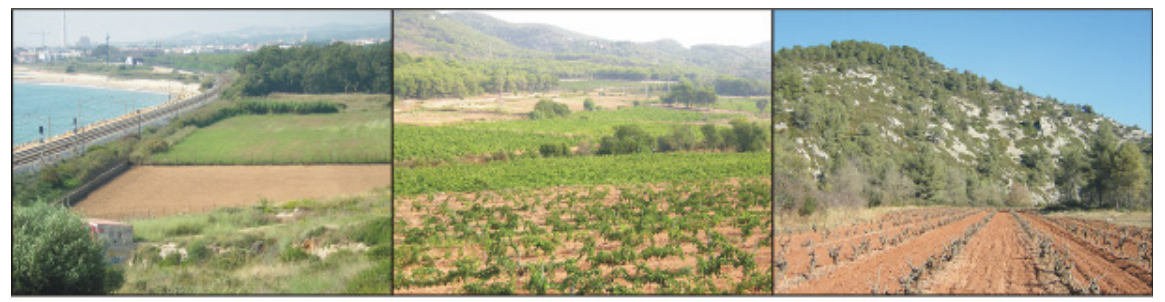

III La huerta de Viarowa y los regallios

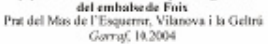

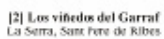
Giand, $\varnothing 2003$

[3] Las bendor adas viticoles

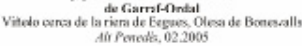

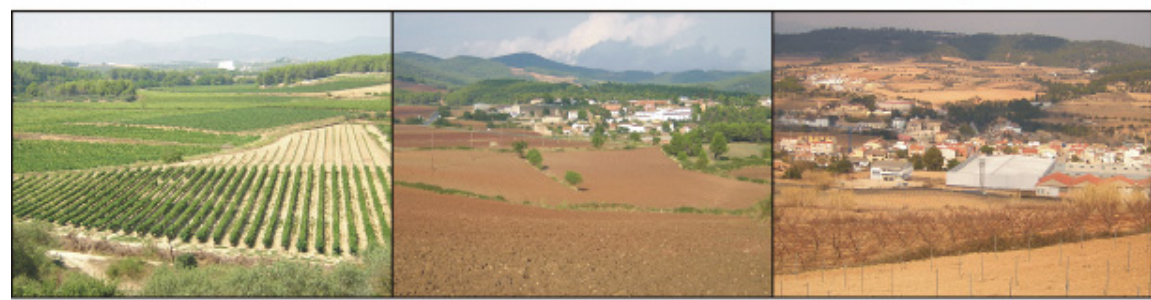

101 Las vithedos det lano del Penedes afeques, Casielikt ila Gom

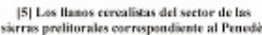
Sank Joande Medicrs, Medioes

16| E1 policultivo de los valles del Amoia

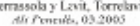

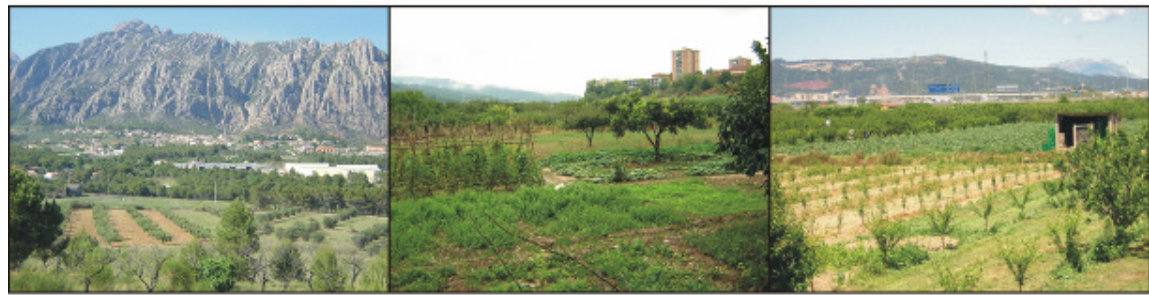

17| Les ulinares del fat de Moatserrat

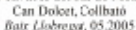

|8| Las frutales del entarno de Martireti

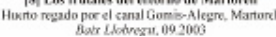

19| Los fretales be ba Vall Baisa
Can Fabuera. Sont Feliu de Lidoregen

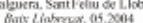


Antología de fotografías de las unidades de paisaje agrario de la Región Metropolitana de Barcelona (II).

Fotografías de Valerià Paül (04.2002-06.2005).
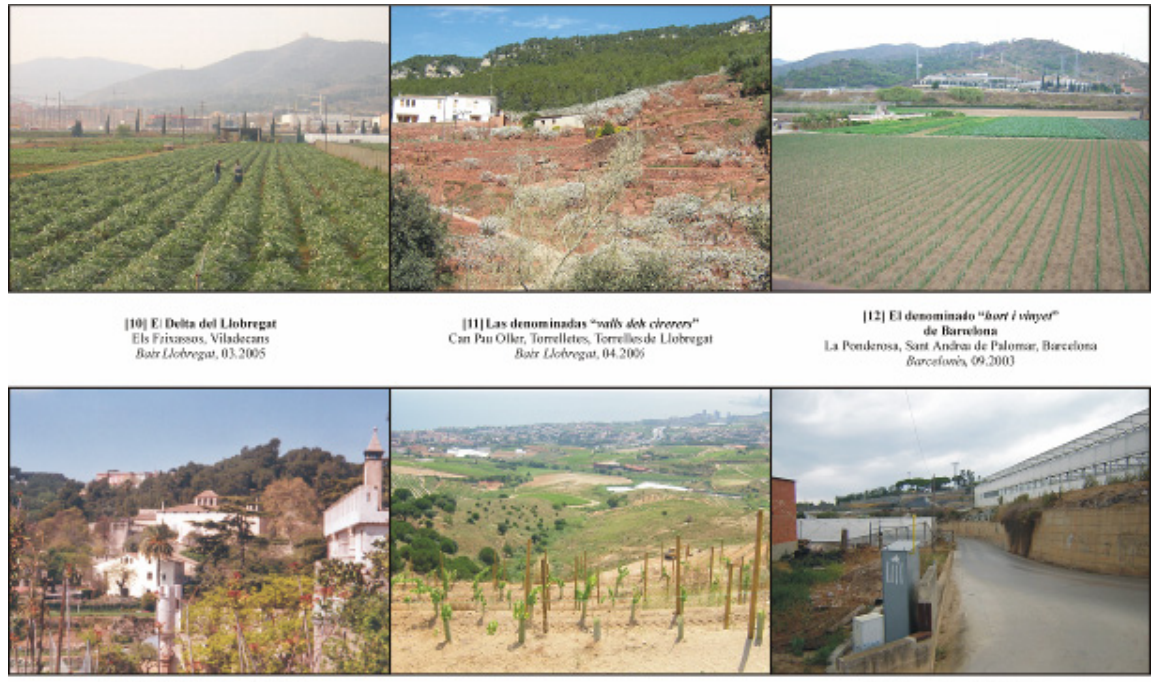

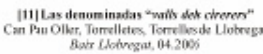

|12| El desenainade "Gevr i whyer

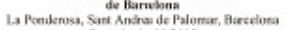

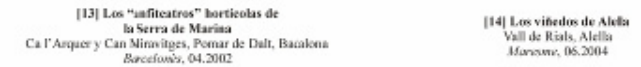

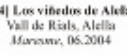

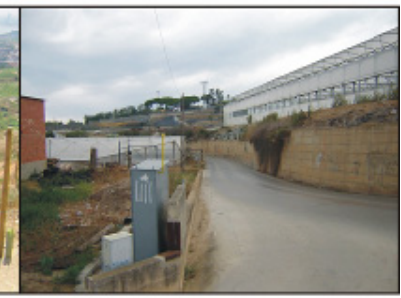

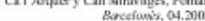

(2) [15] Los euterrs bajo plistioo
del Baix Marsane

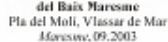

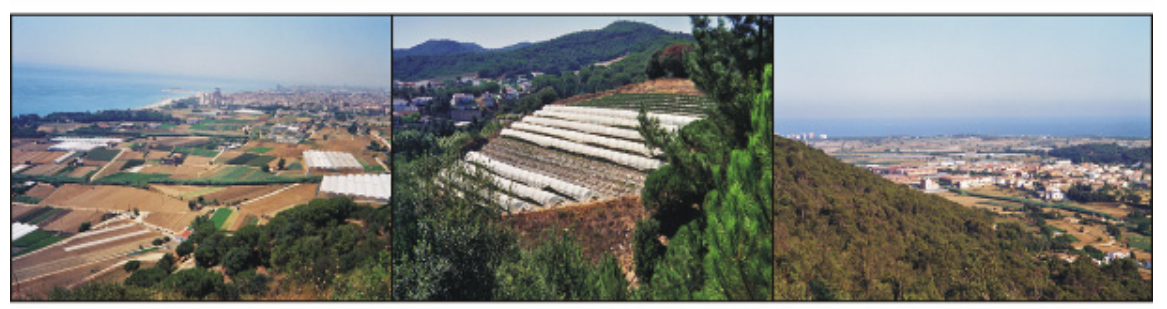

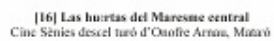

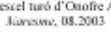

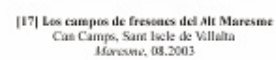

[18) Ea Delta \& a Torderay Hi Detta de la Tordera desde ef coscilite de Palafolls, Palafollts Morssus: 08.2003 
Antología de fotografías de las unidades de paisaje agrario de la Región Metropolitana de Barcelona (y III).

Fotografías de Valerià Paül (04.2002-06.2005).
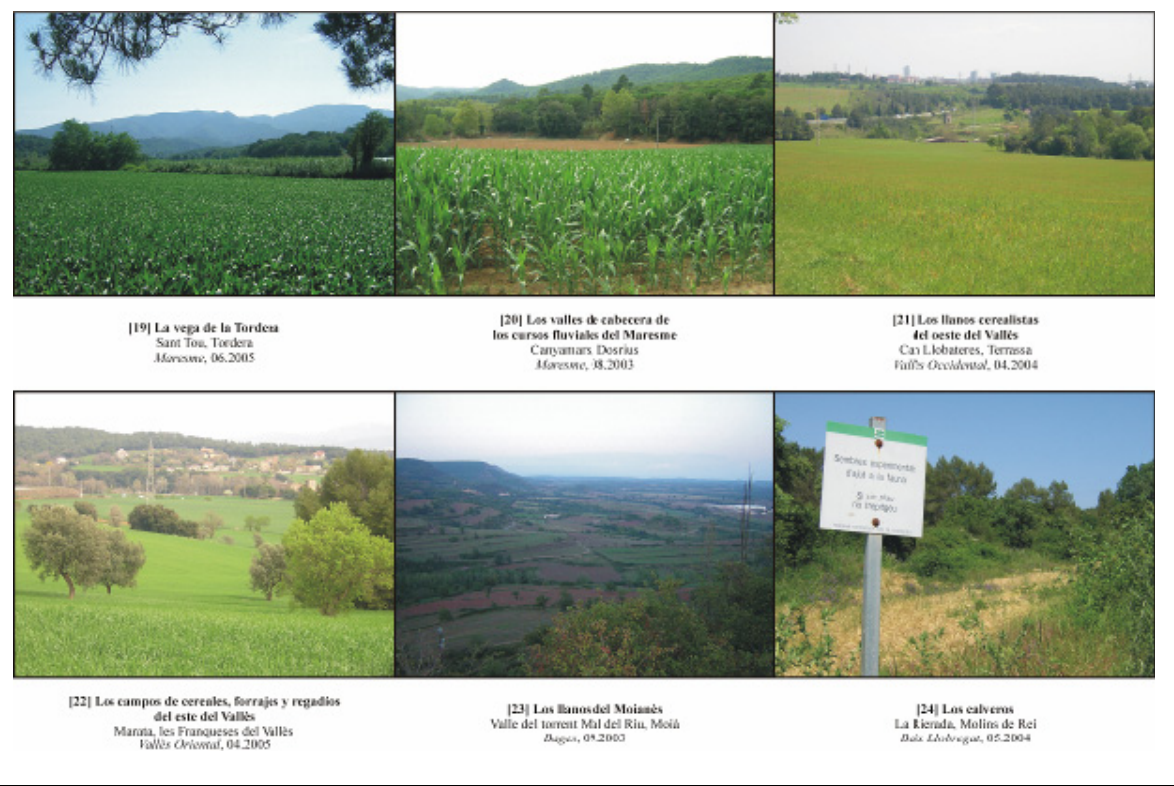